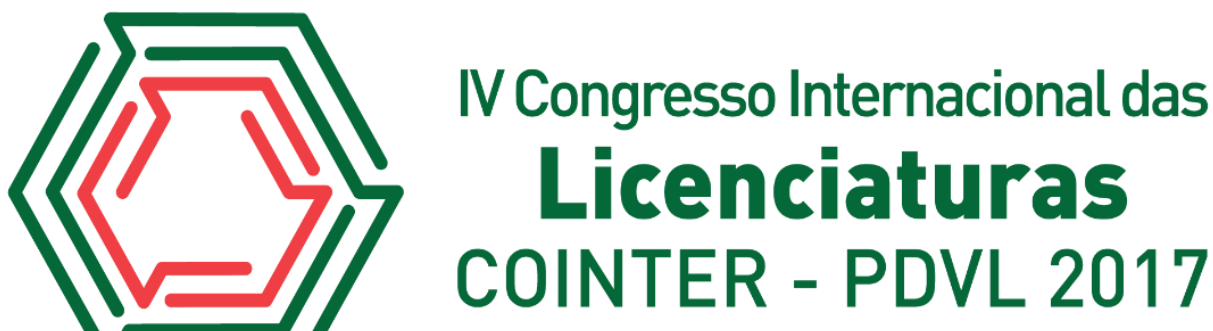

\section{A INFLUÊNCIA DO PROGRAMA DE EDUCAÇÃO TUTORIAL (PET) NA NÃO EVASÃO DOS ESTUDANTES DO CURSO DE LICENCIATURA EM QUÍMICA}

Apresentação: Relato de Experiência

Lucas Oliveira do Rosário ${ }^{1}$; Isabele da Silva Francelino ${ }^{2}$; Fernanda Rodrigues de Lima ${ }^{3}$; Bruno Enedino de Oliveira Silva ${ }^{4}$, Jailson Machado Ferreira ${ }^{5}$

\section{Introdução}

O Programa de Educação Tutorial - PET é desenvolvido através da realização de atividades fundamentadas na tríade: ensino, pesquisa e extensão. O PET é formado por grupos de discentes sob tutoria de um docente os quais são coordenados pela SESu/MEC e fomentados através de bolsas e custeio pelo FNDE. O Manual de Orientações Básicas do PET afirma que o programa,

Têm sérios compromissos epistemológicos, pedagógicos, éticos e sociais. Com uma concepção baseada nos moldes de grupos tutoriais de aprendizagem e orientado pelo objetivo de formar globalmente o aluno, o PET não visa apenas proporcionar ao bolsista e aos alunos do curso uma gama nova e diversificada de conhecimento acadêmico, mas assume a responsabilidade de contribuir para sua melhor qualificação como pessoa humana e como membro da sociedade (p. 3, 2002).

Observa-se, assim, que o PET é um programa de excelência e tem o objetivo de incentivar o discente para proporcionar ao mesmo uma melhor formação. Pretende também minimizar a evasão dos estudantes do curso que é, seguramente, um dos maiores problemas enfrentados pelas instituições de ensino superior.

\section{Relato de Experiência}

\footnotetext{
1 Licenciatura em Química, Instituto Federal de Educação, Ciência e Tecnologia da Paraíba, luca.s2016@hotmail.com

2 Licenciatura em Química, Instituto Federal de Educação, Ciência e Tecnologia da Paraíba, isabelefrancelino@hotmail.com

3 Licenciatura em Química, Instituto Federal de Educação, Ciência e Tecnologia da Paraíba, nanarodrigues621@gmail.com

4 Licenciatura em Química, Instituto Federal de Educação, Ciência e Tecnologia da Paraíba, brunoenedino@hotmail.com

${ }^{5}$ Doutor em Química Inorgânica, Licenciatura em Química, Instituto Federal de Educação, Ciência e Tecnologia da Paraíba, jailsonmf@yahoo.com.br
} 
O grupo PET Química do Instituto Federal de Educação, Ciência e Tecnologia da Paraíba -IFPB é atualmente constituído por um grupo de 9 (nove) discentes do curso de Licenciatura. Dentre os discentes, 2 (dois) estão prestes a se graduar, 4 (quatro) estão na metade do curso e 3 (três) foram selecionados recentemente e estão iniciando o curso de graduação. Dentre os estudantes, relatou-se a influência do PET para abster a evasão no curso de Licenciatura em Química do IFPB:

Discente [A]: Quando ingressei no curso de Licenciatura em Química tinha em mente que não pretendia concluí-lo, pois apesar de ser na área de química, meu objetivo era cursar Engenharia Química. Ainda no primeiro ano do curso surgiu a oportunidade de participar da seleção do PET Química e fui selecionada. Foi onde compreendi a essência do curso através, principalmente, das atividades de ensino. Dessa forma, reconheço que o PET contribuiu em peso para que eu pudesse prosseguir na graduação e estar atualmente em fase de conclusão.

Discente [B]: “O PET teve fundamental importância na minha vida dentro do IFPB. Fui aprovado no processo seletivo (PS) quando ainda estava no segundo período. Desde lá amadureci muito como pessoa e como profissional, pois o PET trabalha muito bem as três áreas que dispõe de atividades para cumprir anualmente: o ensino; a pesquisa e a extensão. Pensava em mudar para o curso de Engenharia Química, mas o PET influenciou-me a seguir no curso e agora quero concluí-lo."

\section{Considerações}

Após os relatos dos integrantes do PET Química IFPB, verificou-se que boa parte dos discentes não pretendiam concluir o curso, por não se identificar na carreira docente. Após estes estudantes ingressarem no programa, ficou evidente o equívoco dos mesmos, pois puderam perceber que possuem perfil para a docência mediante a influência do PET e suas atividades. É importante salientar que o interesse destes estudantes é de grande estímulo para contribuir no processo de formação como futuros profissionais.

\section{Referências}

BRASIL. Ministério da Educação. Manual de orientações básicas do PET. 2002. Disponível em: 〈http://portal.mec.gov.br/sesu/arquivos/pdf/PETmanual.pdf >. Acesso em: 27 de setembro de 2017. 